\title{
Immunohistochemical Analysis of the Extrinsic Apoptosis Process in the Non-Neoplastic and Neoplastic Prostate
}

\author{
Ayşe Burcu iLERi' ', Reşit Doğan KÖSEOĞLU', Fatma MARKOÇ', ilker ETiKAN², Doğan ATILGAN', \\ Faik Alev DERESOY ${ }^{1}$
}

'Department of Pathology, Gaziosmanpasa University School of Medicine, TOKAT, TURKEY, ${ }^{2}$ Department of Biostatistics, Near East University School of Medicine, LEFKOŞA, NORTH CYPRUS, MERSIN 10, TURKEY, ${ }^{3}$ Department of Urology, Gaziosmanpasa University School of Medicine, TOKAT, TURKEY

This study was presented as an oral presentation in the $22^{\text {nd }}$ National Congress of Pathology, 7-11 November 2012, Antalya, Turkey.

\section{ABSTRACT}

Objective: Deviations in the apoptotic process have been demonstrated in prostate carcinogenesis. We aimed to evaluate especially the process of extrinsic apoptosis in the spectrum of neoplastic lesions of the prostate epithelium so as to reveal the variations in the apoptotic process.

Material and Method: The study included 20 benign prostatic hyperplasia, 8 high-grade prostatic intraepithelial neoplasia and 82 prostatic carcinoma patients. Immunohistochemistry was performed on sections obtained from materials of suprapubic prostatectomy, tru-cut biopsy, transurethral resection and radical prostatectomy. While Fas and FasL were evaluated in glandular and stromal areas, DcR1 and FLIP were evaluated in only glandular areas. Intensity and extent of immunostaining for Fas and FasL antibodies were separately scored and both scores were summarized. The total score of $\geq 4$ both for Fas and FasL, expressions of FLIP and DcR1determined in more than 5\% of glandular areas were accepted as positive.

Results: Glandular FasL positivity was observed in 63.8 and $20 \%$ of the cases with prostatic carcinoma and benign prostatic hyperplasia, respectively ( $\mathrm{p}=0.001)$. The loss of stromal Fas expression in PCa was obvious $(\mathrm{p}<0.001)$. FLIP positivity was more frequently seen in high-grade prostatic intraepithelial neoplasia and PCa.

Conclusion: In prostatic carcinoma, decreased stromal Fas expression, contrary to higher glandular FasL positivity, supports the assertion that sensitivity of epithelial and stromal cells to apoptosis and their protective pathways against apoptosis undergo alterations. Increased FLIP expressions in high-grade prostatic intraepithelial neoplasia and prostatic carcinoma can also be interpreted accordingly.

Key Words: Prostate, Carcinogenesis, Fas, FasL, DcR1, FLIP

\section{INTRODUCTION}

Dysregulation of apoptotic mechanisms has an important role in carcinogenesis. The blockages in he apoptotic processes may cause genomic instability, accumulation of mutations and finally uncontrolled cell divisions. The extrinsic apoptotic pathway plays a critical role in immunological and non-immunological elimination of the cells exposed to genomic damage. Death and decoy receptors and their regulators have an extraordinary importance. The novel treatment modalities in prostate cancer have come into question with the detection of death and decoy receptors.

Fas (CD95, Apo-1) is a type 1 membrane receptor of the tumor necrosis factor/nerve growth factor receptor super family. FasL (Fas ligand) is a natural ligand for Fas and a type II transmembrane protein. Fas and FasL complex induces apoptosis in target cells. A variety of cells express Fas. Some of these cells are activated lymphocytes and natural killer

(Turk Patoloji Derg 2018, 34:19-28)

Received : 27.11.2015 Accepted : 09.07.2017 cells. Fas and FasL have also been detected in malignant neoplasms, including melanoma, colon carcinoma, renal cell carcinoma, astrocytoma, esophageal carcinoma, and breast carcinoma. The up-regulation of FasL in malignant cells may play a role in escaping immune surveillance by inducing apoptosis of activated lymphocytes and natural killer cells. It has been shown that FasL is secreted constitutively by prostate carcinoma cells in vitro. Dysregulation of Fas and FasL homeostasis may play a role in the development and progression of prostate carcinoma (1-5). Another receptor family involved in the extrinsic apoptotic pathway is tumor necrosis factor-related apoptosis-inducing ligand (TRAIL) and its receptors (TRAIL-R). TRAIL is an analogue of FasL. TRAIL is expressed on the surface of many normal cells, and up to five types of TRAIL-R have been described. Among them, TRAIL-R1 (DR4) and TRAIL-R2 (DR5) contain a cytoplasmic death region and transmit apoptotic signals. TRAIL-R3 (DcR1) and TRAIL-R4 (DcR2) block intracellular transmission of signals and hence they are

Correspondence: Reşit Doğan KÖSEOĞLU

Gaziosmanpasa University School of Medicine,

Department of Pathology, TOKAT, TURKEY

E-mail: residdogan@hotmail.com Phone: +90 3562129500 
called "decoy receptors" (6-8). FLIP (FLICE inhibitor protein) is a protein with amino acid sequences similar to caspase- 8 and capsase-10. FLIP competes with them for binding to FADD (Fas associated death domain) and inhibits Fas-mediated apoptosis at the subreceptor level (9). Some reports are available on FLIP expression in prostate cancers (10).

In this study, our aim was to reveal the probable alterations in extrinsic apoptotic mechanisms in prostatic cancer tissues.

\section{MATERIAL and METHODS}

After the approval of the local ethics committee was obtained, we retrospectively reviewed the medical files of cases with benign prostatic hyperplasia $(\mathrm{BPH} ; \mathrm{n}=20)$, high-grade prostatic intraepithelial hyperplasia (HGPIN; $\mathrm{n}=8$ ) and prostatic adenocarcinoma (PCa; $\mathrm{n}=82$ ) from the archives of our department. Paraffin blocks and slides of these cases were obtained and reviewed for confirmation of the diagnoses. A total of 110 study participants were diagnosed between 2007 and 2011. Tissue samples of all
$\mathrm{BPH}$ cases were suprapubic prostatectomy specimens, while those of all HGPIN cases were obtained from trucut biopsy materials. The study material of PCa cases were selected from radical prostatectomy $(n=12)$, transurethral resection $(n=2)$ and tru-cut biopsy $(n=68)$ specimens. PCa cases were classified into three groups according to Gleason total score as the differentiated group (DPCa; score 6), moderately differentiated group (MDPCa; score 7) and poorly differentiated group (PDPCa; score 8-10).

\section{Immunohistochemistry}

Immunohistochemical analyses were performed on paraffin sections $4 \mu \mathrm{m}$ thick. Characteristics of primary antibodies used in the analysis are shown in Table I. The sections were boiled in citrate buffer solution $(\mathrm{pH}=6)$ for the epitope retrieval process. Immunohistochemical evaluation for all antibodies was performed on areas that demonstrated the most optimal immunostaining. Cytoplasmic and membranous staining for both glandular and stromal cells was considered as significant (Figure 1A-D). Intensity and extent of immunostaining for Fas and FasL antibodies were separately scored according to the following scheme
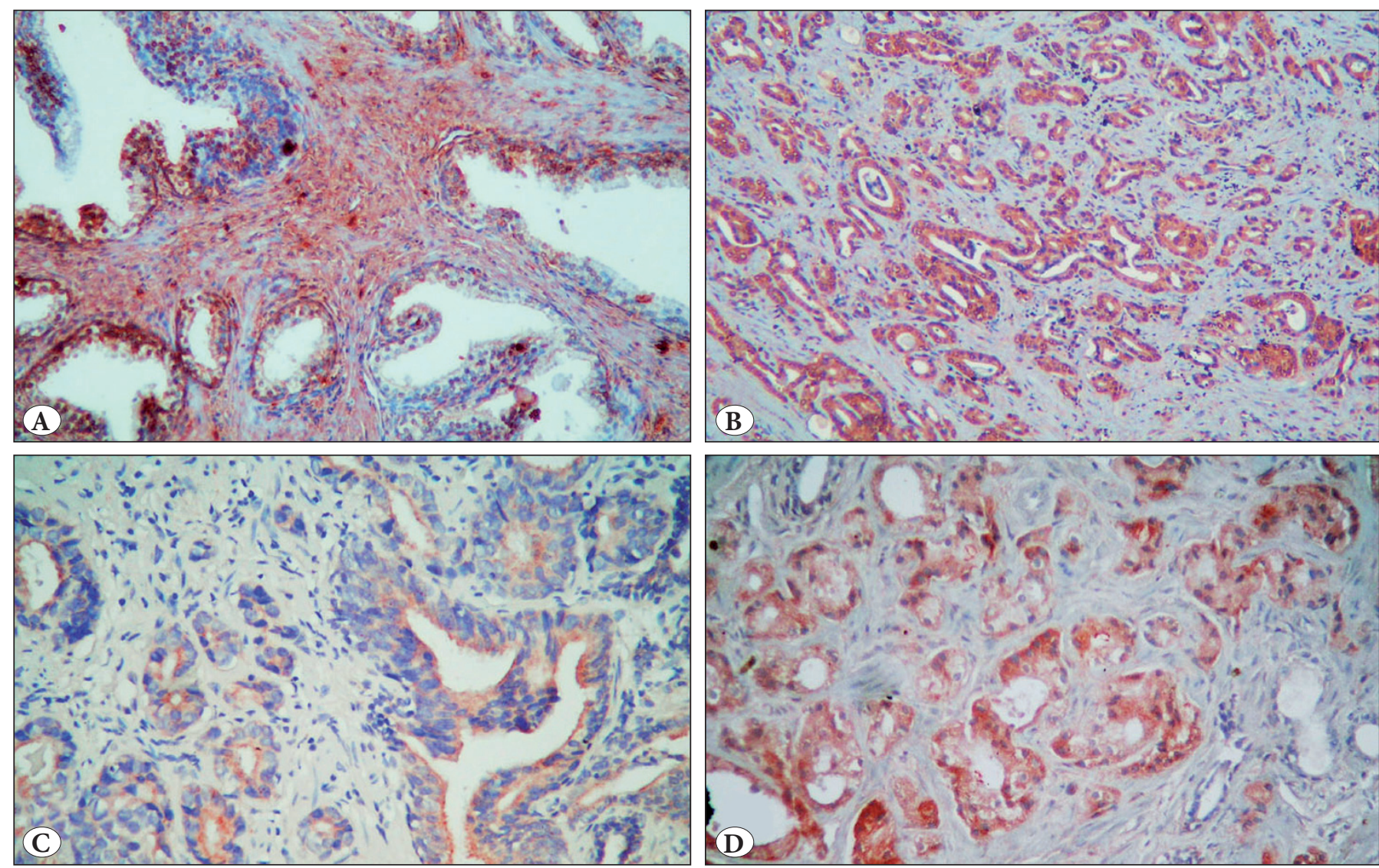

Figure 1: A) Glandular and stromal Fas expressions in BPH (Fas; x20). B) Glandular FasL expression in PCa (FasL; x10). C) Membranous DcR1 expressions in PCa (DcR1; x30). D) FLIP expression in PCa (FLIP; x30). 
(Table II). Both scores were summarized and cases with a total score of $\geq 4$ both for Fas and FasL were accepted as positive. Since HGPIN is a stroma-free lesion, stromal expressions for Fas and FasL were not evaluated in this group. In analyses of FLIP and DcR1, cytoplasmic staining of glandular epithelial cells was considered to be significant and immunostaining for these two antibodies in more than $5 \%$ of glandular areas was accepted as positive. Tonsil tissue was used as the positive control tissue for all antibodies and phosphate buffer solution (PBS) instead of primary antibody as the negative control in the incubation period.

\section{Statistical Analysis}

One-way-ANOVA for age was performed while categorized variables were analyzed by chi-square. Fisher's exact test was used if the number of cells with expected frequencies less than five did not exceed $20 \%$ of all cells. The independent samples t-test was used for comparison of the mean age between the groups. A $p$ value $\leq 0.05$ was accepted as significant.

\section{RESULTS}

The mean age of the study population was 68.4 (range; 47-81) years. The mean ages of the BPH, HGPIN and PCa groups (67.3, 66 and 69, respectively) were close to each other $(p=0.324)$. The distribution of cases in the PCa group according to total Gleason scores was $\mathrm{n}=26(31.7 \%)$ for DPCa, $\mathrm{n}=24$ (29.3\%) for MDPCa and $\mathrm{n}=32$ (39\%) for PDPCa. Mean ages of the groups according to Gleason grade in PCa were 66.2, 69.5 and 70.8, respectively. Mean ages of DPCa and PDPCa showed a statistically significant difference $(p<0.015)$. A statistically significant relationship was determined between age and stromal FasL expression in the BPH group. Stromal FasL positive cases' mean age (63.5) was lower than negative ones (69.8) in BPH ( $t=2.673$, $p=0.016)$. No significant relationship was detected between mean age and immunohistochemical parameters in other groups.

\section{Fas Analysis}

Glandular Fas expression was not seen in cases of HGPIN while groups of BPH and PCa showed glandular Fas expressions at rates of $20 \%$ and $9.8 \%$, respectively. Although a statistical significant difference for glandular Fas expression between the groups could not be demonstrated, the BHP group showed a higher rate of glandular Fas expression than those of other groups $(p=0.340)$ (Table III, Figure 2).

Stromal Fas expression showed a significant difference between BPH and PCa. Stromal Fas expression was detected in $45 \%$ (9 cases) of the cases in the $\mathrm{BPH}$ group

Table I: Primary antibodies.

\begin{tabular}{lllll}
\hline Antibodies & Dilution & Clone & Trade Mark & Incubation time \\
\hline Fas (CD95) Ab-3 & $1 / 15$ & GM30 Mouse monoclonal & ThermoScientific & 60 minutes $\left(37^{\circ} \mathrm{C}\right)$ \\
\hline FasL (N-20) & $1 / 50$ & Rabbit Polyclonal & Santa Cruz & Overnight $\left(4^{\circ} \mathrm{C}\right)$ \\
\hline Anti-CASP8 (FLIP) & $1 / 50$ & Rabbit Polyclonal & antibodies-online Inc. & Overnight $\left(4^{\circ} \mathrm{C}\right)$ \\
\hline DcR1 (L19) & $1 / 50$ & Mouse Monoclonal & Santa Cruz & Overnight $\left(4^{\circ} \mathrm{C}\right)$ \\
\hline
\end{tabular}

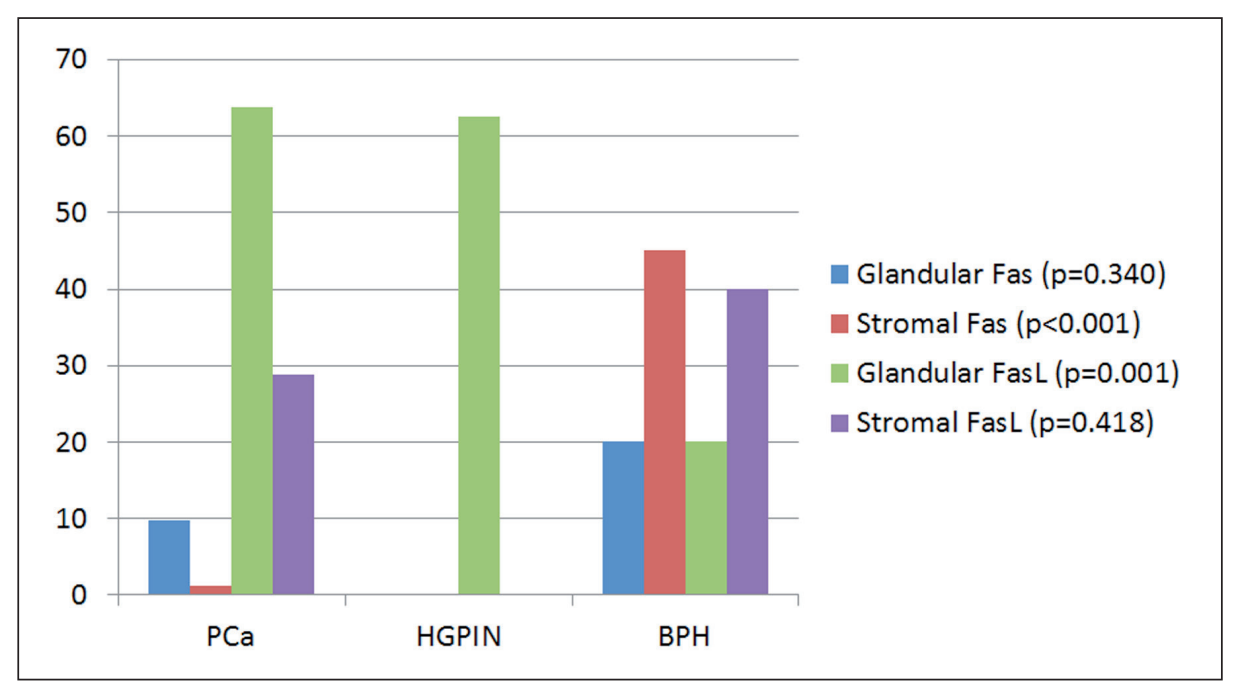

Figure 2: Fas and FasL expression rates by groups. 
while the positivity rate was $1.2 \%$ ( 1 case) in the PCa group. Stromal Fas expression had statistical significance in our study $(p<0.001)$ (Table III, Figure 2).

Glandular Fas expression was only seen in 8 cases (9.8\%). The rates of glandular Fas expression were similar in the DPCa, MDPCa and PDPCa groups (11.5\%, 8.3\% and 9.4\%, respectively) $(p=0.999)$ (Table IV, Figure 3 ).

Stromal Fas expression was noted in only one case (1.2\%) in the PCa group $(p=0.296)$.

\section{FasL Analysis}

Glandular FasL expression could not be evaluated in 2 cases in the PCa group because of technical reasons. Glandular FasL expression showed a statistically significant difference between the groups. Eighty percent of the cases of BPH were negative for FasL. The rates of positivity in HGPIN and PCa were 62.5 and $63.8 \%$, respectively. The difference for FasL expression between BPH and the groups representing neoplastic transformation (HGPIN and PCa) was statistically significant $(p=0.001)$ (Table III, Figure 2 ).

Stromal FasL expression did not show a significant difference between BPH and PCa. Stromal FasL expression was seen in $28.8 \%$ of PCa cases while the other groups showed stromal FasL expression at rates of 50\%, approximately (Table III, Figure 2).

Glandular FasL expression was detected in 51 (63.8\%) of 80 cases in the PCa group. A significant intergroup difference for glandular FasL expression was not seen between groups

Table II: The semiquantitative grading scheme used for analysis of Fas and FasL immunostaining.

\begin{tabular}{lccc}
\hline Wideness & Score & Intensity & Score \\
\hline No staining or $<\% 10$ & 0 & No staining & 0 \\
\hline $10 \%-50 \%$ & 1 & Mild & 1 \\
\hline $50 \%-75 \%$ & 2 & Moderate & 2 \\
\hline$>\% 75$ & 3 & Severe & 3 \\
\hline
\end{tabular}

Table III: The distribution of positivity rates for the apoptosis related antibodies according to the study groups.

\begin{tabular}{lcccccc}
\hline Groups & $\begin{array}{c}\text { Glandular } \\
\text { Fas }(+)\end{array}$ & $\begin{array}{c}\text { Stromal } \\
\text { Fas }(+)\end{array}$ & $\begin{array}{c}\text { Glandular } \\
\text { FasL }(+)\end{array}$ & $\begin{array}{c}\text { Stromal } \\
\text { FasL }(+)\end{array}$ & FLIP(+) & DcR1(+) \\
\hline BPH (20 cases) & $4(20 \%)$ & $9(45 \%)$ & $4(20 \%)$ & $8(40 \%)$ & $1(5 \%)$ & $2(10 \%)$ \\
\hline HGPIN (8 cases) & 0 & $\begin{array}{c}\text { Stromal expression } \\
\text { was not evaluated } \\
\text { in this category. }\end{array}$ & $5(62,5 \%)$ & $\begin{array}{c}\text { Stromal expression } \\
\text { was not evaluated } \\
\text { in this category. }\end{array}$ & $3(37,5 \%)$ & 0 \\
\hline PCa (82 cases) & $8(9,8 \%)$ & $1(1,2 \%)$ & $51(63,8 \%)$ & $23(28,8 \%)$ & $15(18,8 \%)$ & $8(9,8 \%)$ \\
\hline Total (110 cases) & $12(100 \%)$ & $10(100 \%)$ & $60(100 \%)$ & $31(100 \%)$ & $19(100 \%)$ & $10(100 \%)$ \\
\hline Statistic & $x^{2}=2.792$, & $x^{2}=34,440$ & $x^{2}=12.572$, & $x^{2}=0,947 p=0.331$ & $x^{2}=4.448$, & $x^{2}=0.864$, \\
Statistic (Fisher exact test) & $p=0.248$ & $p<0.001$ & $p=0.002$ & $p=0.108$ & $p=0.649$ \\
\hline
\end{tabular}

BPH: Benign prostatic hyperplasia, HGPIN: High-grade prostatic intraepithelial neoplasia, Pca: Prostatic carcinoma.

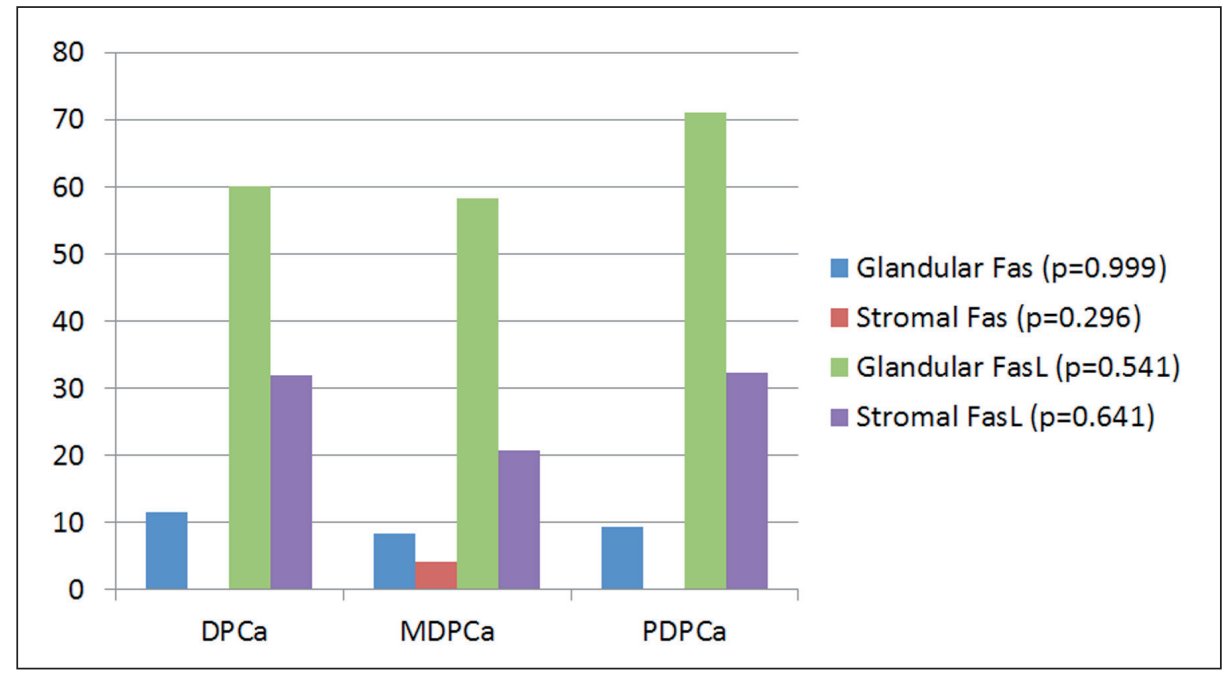

Figure 3: Fas and FasL expression rates according to the Gleason grades in PCa group. 
as categorized by Gleason scores $(p=0.541)$. The rates of glandular FasL positivity in DPCa, MDPCa and PDPCa were $60 \%, 58.3 \%$ and $71 \%$, respectively (Table IV, Figure 3 ).

Stromal FasL positivity in the PCa group was determined in 23 cases (28.8\%). Stromal FasL positivity rates in each subgroup categorized by total Gleason scores were close to each other $(p=0.641)$ (Table IV, Figure 3 ).

\section{DcR1 Analysis}

There was no difference for DcRlexpression between the groups ( $p=0.999$ ). The highest rate for DcR1 positivity was $10 \%$ among all groups. Stromal and nuclear expressions of DcR1 were not seen in any group (Table III, Figure 4).

The DcR1 positivity rate was $9.8 \%$ (8 cases) in the $\mathrm{PCa}$ group. $3.8 \%$ of DPCa cases were positive for DcR1, while $15.6 \%$ of PDPCa cases showed DcR1 positivity $(p=0.329)$.
DcR1 positivity was $8.3 \%$ in the MDPCa group (Table IV, Figure 5).

\section{FLIP Analysis}

FLIP expression could be evaluated in only 80 cases in the PCa group. Two cases were excluded due to technical reasons. Only $5 \%$ of the cases in the BPH group showed positivity for FLIP while the rates of FLIP positivity in the HGPIN and PCa groups were $37.5 \%$ and $18.8 \%$, respectively $(p=0.102)$. Stromal and nuclear positivity for FLIP was not seen in any case (Table III, Figure 4).

Fifteen cases (18.8\%) were positive for FLIP in the PCa group. FLIP positivity according to Gleason grade did not show a significant intergroup difference $(p=0.262)$ (Table IV, Figure 5).

Table IV: The distribution of positivity rates for the apoptosis related antibodies according to the total Gleason scores in PCa group.

\begin{tabular}{|c|c|c|c|c|c|c|}
\hline $\begin{array}{l}\text { PCa categories according to total } \\
\text { Gleason Score }\end{array}$ & $\begin{array}{l}\text { Glandular } \\
\text { Fas }(+)\end{array}$ & $\begin{array}{l}\text { Stromal } \\
\text { Fas }(+)\end{array}$ & $\begin{array}{l}\text { Glandular } \\
\text { FasL }(+)\end{array}$ & $\begin{array}{l}\text { Stromal } \\
\text { FasL }(+)\end{array}$ & FLIP (+) & $\operatorname{DcR} 1(+)$ \\
\hline $\begin{array}{l}5-6 \\
\text { DPCa ( } 26 \text { cases })\end{array}$ & $3(11,5 \%)$ & 0 & $15(60 \%)$ & $8(32 \%)$ & $4(16 \%)$ & $1(3,8 \%)$ \\
\hline $\begin{array}{l}7 \\
\text { MDPCa ( } 24 \text { cases) }\end{array}$ & $2(8,3 \%)$ & $1(4,2 \%)$ & $14(58,3 \%)$ & $5(20,8 \%)$ & $7(30,4 \%)$ & $2(8,3 \%)$ \\
\hline $\begin{array}{l}\text { 8-10 } \\
\text { PDPCa (32 cases) }\end{array}$ & $3(9,4 \%)$ & 0 & $22(71 \%)$ & $10(32,3 \%)$ & $4(12,5 \%)$ & $5(15,6 \%)$ \\
\hline Total (82 cases) & $8(9,8 \%)$ & $1(1,2 \%)$ & $51(63,8 \%)$ & $23(28,8 \%)$ & $15(18,8 \%)$ & $8(9,8 \%)$ \\
\hline Statistic & $\begin{array}{l}x^{2}=0.154 \\
p=0.926\end{array}$ & $\begin{array}{l}x^{2}=2.405 \\
p=0.300\end{array}$ & $\begin{array}{l}x^{2}=1.156 \\
p=0.561\end{array}$ & $\begin{array}{l}x^{2}=1.049 \\
p=0.592\end{array}$ & $\begin{array}{l}x^{2}=3.006 \\
p=0.222\end{array}$ & $\begin{array}{l}x^{2}=2.339, \\
p=0.311\end{array}$ \\
\hline Statistic (Fisher exact test) & $p=0.999$ & $p=0.296$ & $p=0.541$ & $p=0.641$ & $p=0.262$ & $p=0.329$ \\
\hline
\end{tabular}

Pca: Prostatic carcinoma, DPCa: Differentiated prostatic carcinoma, MDPCa: Moderately differentiated prostatic carcinoma; PDPCa: Poorly differentiated prostatic carcinoma.

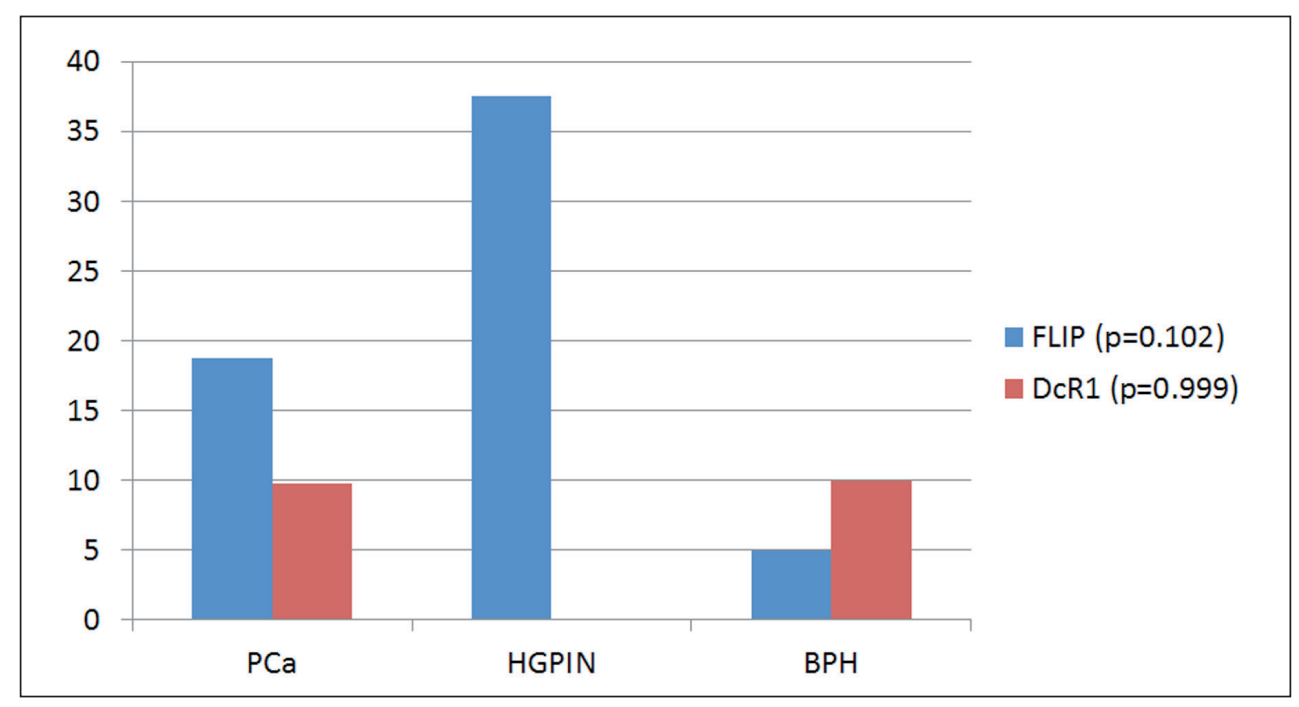

Figure 4: FLIP and DcR1 expression rates by the groups. 


\section{DISCUSSION}

Many authors have reported that Fas expression manifested differences in different cellular components of the prostate gland and Fas expression decreased in tumoral prostate tissue when compared with the normal prostate gland. However some publications have revealed the lack of a difference in expression rates between different cellular components of the gland and also between the normal and tumoral prostate gland (1-5). In a study by Kim et al., the authors stated that the normal prostate gland and all PIN lesions demonstrated strong Fas expression and suggested that interruption of Fas-mediated apoptosis caused by decreased or even lack of Fas expression in prostate cancer is a late-onset manifestation of prostate carcinogenesis (4). However Jiang et al. reported that Fas expression was seen more frequently in HGPIN (36\%) and prostate cancers $(50 \%)$ when compared with benign prostatic tissue (14\%) (5). Sasaki et al. indicated lack of any difference between benign and malignant prostate tissues (3). On the contrary, Kim et al. reported absence of Fas expression in $44 \%$ of the prostatic adenocarcinoma samples (4). According to the literature, loss of Fas expression was not a stable finding in different prostatic cancer series. One explanation of this phenomenon can be silencing of promoter regions via hypermethylation. According to a study, the hypermethylation rate of the Fas gene promoter region was $12.5 \%$ (11). Our glandular Fas immunostaining results contribute to literature data. Twenty percent of the cases with $\mathrm{BPH}$ yielded Fas positive results, while glandular Fas positivity was not detected in any of the cases with HGPIN. However $9.8 \%$ of the cases with PCa demonstrated glandular Fas positivity. In the PCa group, glandular Fas expression was less frequently seen without any statistically significant intergroup difference $(P=0.340)$. Nonobservance of glandular Fas positivity in cases with HGPIN and lower rates of Fas positivity in the PCa group might suggest that loss of glandular Fas positivity can be evaluated as a manifestation of prostate carcinogenesis. However, our glandular Fas positivity rate $(20 \%)$ in the BPH group was lower than that cited in the literature. Higher Fas expression rates were reported especially in benign prostatic tissue samples. Only Jiang et al. obtained Fas expression rates (14\%) close to ours (5). However, higher rates had been detected in comparison with benign cases in their prostatic adenocarcinoma series. These outcomes have given rise to the question why antiapoptotic resistance develops in cancer cells despite increased, unchanged or insignificantly decreased Fas expression in malignant cells relative to their benign counterparts. Jiang et al. also drew attention to this issue. In their study, malignant prostatic tissues and HGPIN samples had demonstrated increased Fas expression. Jiang et al. reported an interesting observation. They had detected cytoplasmic rather than membranous Fas positivity in malignant prostatic tissues and HGPIN samples (5). Indeed, the authors remarked that membranous Fas expression should be present for the apoptotic process, while cytoplasmic Fas positivity indicated an impaired apoptotic mechanism (12-14). We also detected mostly cytoplasmic Fas positivity. If cytoplasmic staining is considered to represent an altered Fas apoptotic pathway, one must deduce that our cases were mostly devoid of Fas expression and Fas positive cases had dysfunctional Fas pathways. In this case, one should conceive that the Fas pathway was absent or altered in all benign and malignant cases included in our study. It seems not possible to assert that Fas expression was absent or the Fas pathway was impaired in all of the cases in our series.

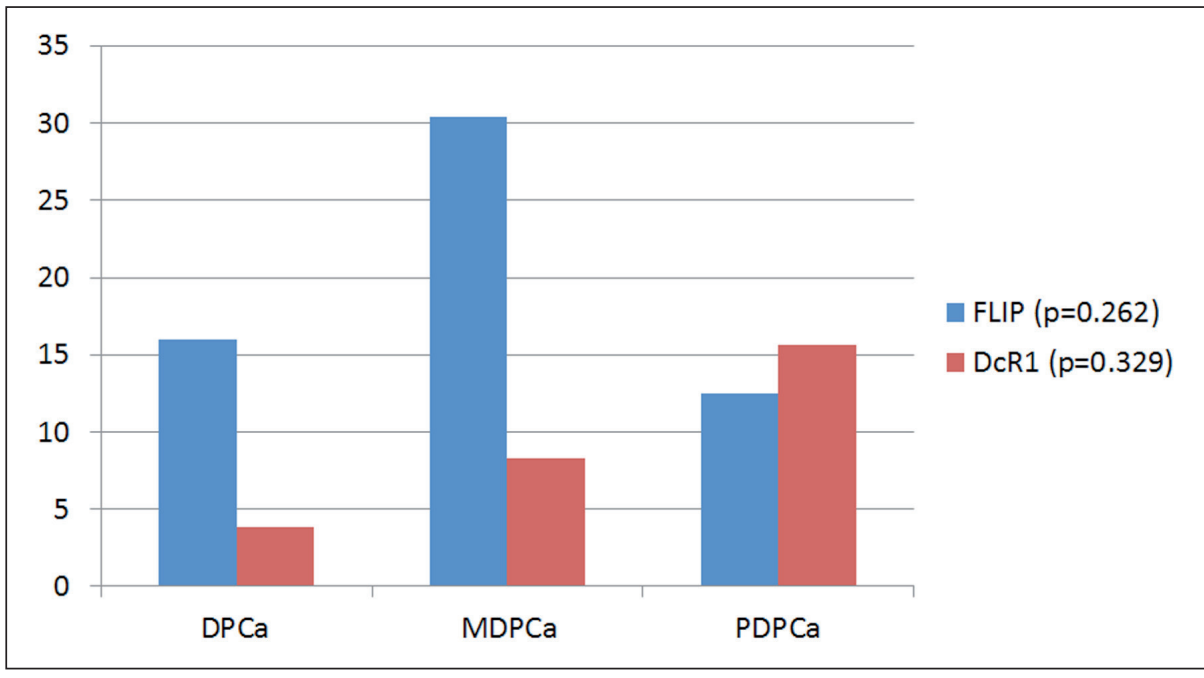

Figure 5: FLIP and DcR1 expression rates according to the Gleason grades in the PCa group. 
In our study, we also evaluated Fas expression by stromal cells. Relative to cases with $\mathrm{BPH}$ (45\%), a marked loss of stromal Fas expression was seen in the PCa group $(1.2 \%)(p<0.001)$. Recently, the role of stromal cells in carcinogenesis has been more clearly understood and many researchers have drawn the attention to the role of stromal cells in prostate carcinogenesis and especially their impact on promoting tumoral invasiveness (15). Increased vulnerability of stromal cells to destructive processes facilitates tumoral invasion. Therefore, an increase in Fas expression by stromal cells can also facilitate tumoral invasion. However, our results seem to contradict these findings. In any event, some data related to prostate carcinogenesis have indicated that loss of stromal Fas expression might have a role in prostate carcinogenesis. Microarray profiles of stromal tissue samples of the prostate glands of the elderly have demonstrated the presence of dysregulations related to some factors derived from stromal cells $(16,17)$. Alterations in membrane-bound molecules of stromal cells and their secreted molecules can exert important effects on malignant transformation (16-18). Loss of stromal Fas confers resistance on stromal cells at least for a while against apoptosis and may maintain some functions that will contribute to tumoral progression. Other probable mechanisms related to development of resistance to the apoptotic process despite increased Fas expression in tumoral cells are as follows: production of soluble Fas which neutralizes FasL, overexpression of bcl-2, overexpression of Fas-associated phosphatase 1 which interacts with the suppressive component of Fas, overexpression of FLIP which inhibits Fas-associated apoptosis and mutations in the primary structure of Fas, caspase- 8 and caspase-10 (2, 19-28). From these outcomes one can infer that largerscale studies should be performed to reveal the state of Fas expression in benign and malignant prostatic lesions.

In a study by Jiang et al., Fas and FasL expressions were analyzed. FasL expression demonstrated marked increases in benign prostate, HGPIN and prostate cancer tissue when compared with Fas expression (5). FasL expression rates in HGPIN and malignant prostate tissues were 92 and $97 \%$, respectively and conspicuously higher relative to benign prostate tissues (49\%) (5). Overexpression of FasL in tumor cells can protect tumor cells against the effects of cytotoxic T-lymphocytes and natural killer cells. Results of some in vitro cell culture studies support the above mentioned assertion $(1,29,30)$. In our study, glandular FasL expression demonstrated significant differences between malignant and benign cases $(p=0.001)$. Glandular FasL expression was detected in cases with BPH (20\%), HGPIN (62.5\%) and PCa $(63.8 \%)$ in respective percentages. According to our results, increased FasL expression can be evaluated as a sign of prostate carcinogenesis starting from the HGPIN stage.

In our study, though a significant difference was not detected between groups as for stromal FasL expression, higher loss of stromal FasL expression in the PCa group relative to the $\mathrm{BPH}$ group was a remarkable finding. Younger cases of $\mathrm{BPH}$ showed significantly more expression of stromal FasL than the older cases, in our study $(p=0.016)$. In the PCa group, an increase in glandular FasL expression despite loss of stromal FasL expression can be meaningful in that this condition facilitates the invasion/infiltration process.

Intragroup analysis in the PCa group according to Gleason grade categories with respect to Fas and FasL expressions did not demonstrate a significant difference regarding glandular and stromal expressions, which indicates the presence of a homogenicity for expressions of Fas and FasL in the PCa group.

The idea of treatment with activation of apoptosis via these receptors whose presence has been demonstrated in vitro in prostate cancer cell strains has been evaluated as an attractive treatment modality (6-8). Since, TNF- $\alpha$ and FasL, have more toxic side effects than TRAIL, TRAIL is thought to be a safer and more reliable therapeutic agent (31). On the other hand, nearly $60 \%$ of malignancies seen in human beings are resistant to TRAIL $(32,33)$. Though the mechanism of this resistance is not known for sure, this resistance was suggested to occur by containment of decoy receptors in normal cells in competition with death receptors (34) or the presence of apoptosis-inhibitor molecules like $\operatorname{FLIP}(24,35)$.

Outcomes of the study investigating the correlations between TRAIL profile and resistance to TRAIL (36, 37) have indicated that expression of the DcR2 receptor absolutely resulted in resistance to TRAIL despite the presence of death receptors. Conversely, lack of expression of decoy receptors in cancer cells was associated with TRAIL sensitivity. Sanlioglu et al. demonstrated the presence of death and decoy receptors in both benign and malignant prostate tissues (38). These receptors were specific to epithelial cells and they were not observed in stromal cells. DcR2 receptors were expressed in increasing amounts both in malignant and benign groups. However, expressions of both TRAIL and its receptors demonstrated a marked increase in prostate cancer. Expression profiles of both TRAIL and TRAIL-R may have a critical value in the discrimination between benign and malignant tissues and also in the TRAIL-mediated gene therapy (38). Increased DcR2 receptor expression may complicate 
this treatment approach $(36,37)$. Ionizing radiation and classical chemotherapeutic agents reinforce TRAILinduced apoptosis (39-41). Therefore in prostate cancers with increased DcR2 receptor expression, treatment with ionizing radiation and chemotherapeutics might be useful so as to overcome resistance to TRAIL (38). Anees et al. reported that expression of TRAIL increased in the tumoral parenchyma, while it got lost in the stromal tissue (18). They observed that significant absence of TRAIL expression in prostate cancer was associated with life-expectancy. High grade prostate cancers exhibit more severe stromal cell proliferation (42). Changes in the composition of stromal cells may also indicate alterations in the interactions between stroma and parenchyma. Anees et al. reported that loss of expression of TRAIL in stromal tissue is an independent parameter effective on the expectation of disease-free life (18). It has been suggested that alterations emerging in stromal environment with age may accelerate the process of prostate carcinogenesis $(43,44)$. Anees et al. asserted a tumor suppressive role of stromal TRAIL expression in prostate carcinogenesis (18). Anees et al. explained their hypothesis by a decrease in stromal TRAIL levels during the course of malignant transformation and the presence of a direct correlation between stromal TRAIL expression and disease-free life-span (18). Anees et al. reported higher FLIP levels in prostate cancer patients. It has been speculated that over-expression of FLIP can exert a clear-cut impact on the inhibition of apoptosis despite increased death receptor and TRAIL levels while conversely, a decrease in death receptors may result in net decreases in apoptotic activity irrespective of lower levels of FLIP expression (18). Anees et al. concluded that the loss of death receptor was associated with higher Gleason score and advanced age ( $\geq 60$ years). Although decrease in TRAIL-mediated apoptosis with advanced age and higher Gleason scores is accompanied by a decrease in FLIP expression, a decrease in death receptors is the determinative factor. It has been suggested that loss of stromal TRAIL expression is seen in malignant transformation, which is also strongly correlated with an unfavorable prognosis (18).

In our study, DcR1 expression was not seen in the HGPIN group while in other groups DcR1 expression was very close to each other. Though any intra-group significant difference did not emerge in the PCa group, DcR1 expression in the DPCa, MDPCa and PDPCa groups was seen at a rate of $3.8 \%, 8.3 \%$ and $15.6 \%$, respectively $(P=0.329)$. According to our study, rates of DcR1 positivity increase contrary to decrease in the degree differentiation in prostatic adenocarcinoma. This result may demonstrate -though partially- the potential impact of DcR1 on the progression of prostate cancer. In our study, stromal DcR1 expression was not seen in any of the cases.

Increased FLIP expression has been reported in from metastatic prostate cancer foci rather than primary foci (45). Increased FLIP expression has been also demonstrated in other malignant neoplasms relative to normal tissues (21-24). Kim et al. reported that cytoplasmic and nuclear FLIP expression was seen in nearly all of the benign and malignant prostatic tissue samples, without any difference between benign and malignant tissue samples (4). In our study FLIP positivity was more frequently seen in the HGPIN and PCa groups when compared with the BPH group (37.5, \%18.8 and $5 \%$, respectively) although the difference was statistically insignificant $(P=0.102)$. This finding of ours indicates that the inhibition of apoptosis has a role in malignant transformation. No intra-group difference was observed in the PCa group as for FLIP expression, and the PCa group can be said to demonstrate homogenous FLIP expression as is the case with Fas and FasL expressions.

We have noticed that different scoring systems are used in various studies in the literature. Our scoring system was modified from some of these scoring systems. Jiang et al. scored their immunoexpressions according to staining intensity and extensity. Weak, unequivocal-moderate and strong intensities were scored as 1,2 and 3, respectively, while extensity was evaluated from $5 \%$ to $100 \%$. Statistical analysis was performed on the basis of this scoring system. They did not use a cut-off value for positivity (5). Şanlıoğlu et al. scored both of intensity and distribution of immunostaining in their study. Their scoring system was as follows; 0 ; negative, 1 ; weak, 2 ; moderate, 3 ; strong staining for intensity, while the distribution scale was $0 ;<10 \%, 1$; $10 \%-40 \%, 2 ; 40 \%-70 \%$ and $3 ;>70 \%$. A cut-off value for positivity was not used in their study (38). Anees et al. used the values of $<10 \%, 10-30 \%$ and $>30 \%$ for distribution of staining and the values of weak; 1 , moderate; 2 and strong; 3 for staining intensity (18). We have determined our own scoring system by modifying the scoring systems (Table II) and we have used a cut-off value in our study.

As can be inferred from the outcomes of our study, variations in the apoptotic process occur in benign and malignant lesions of the prostatic parenchyma. During carcinogenesis, genetic and molecular interactive changes are observed in the parenchymal and stromal cells of the prostate. Our results indicate that FasL expression by glandular cells occurs in the stage of HGPIN during prostate carcinogenesis. Decreased expression of Fas by stromal cells detected in our study opposes alterations 
facilitating anticipated tumoral invasion, while it might also represent a variation that might prolong the lifespan of the stromal cell so as to contribute to malignant transformation. However, FLIP expression in glandular cells suggests that anti-apoptotic effectiveness is gained during carcinogenesis. Another anti-apoptotic mechanism of resistance may be acquired by increased DcR1 expression observed with decreases in the degree of differentiation in cases with malignancies.

Our outcomes indicate that anti-apoptotic mechanisms play important roles in prostate carcinogenesis.

\section{CONFLICT of INTEREST}

The authors declare no conflict of interest.

\section{ACKNOWLEDGEMENT}

This study was supported by Gaziosmanpaşa University Scientific Research Projects Committee (Project No: 2010/01).

\section{REFERENCES}

1. Liu QY, Rubin MA, Omene C, Lederman S, Stein CA. Fas ligand is constitutively secreted by prostate cancer cells in vitro. Clin Cancer Res. 1998;4:1803-11.

2. Leithäuser F, Dhein J, Mechtersheimer G, Koretz K, Brüderlein S, Henne C, Schmidt A, Debatin KM, Krammer PH, Möller P. Constitutive and induced expression of APO-1, a new member of the NGF/TNF receptor superfamily, in normal and neoplastic cells. Lab Invest. 1993;69:415-29.

3. Sasaki Y, Ahmed H, Takeuchi T, Moriyama N, Kawabe K. Immunohistochemical study of Fas, Fas ligand and interleukin-1 beta converting enzyme expression in human prostatic cancer. $\mathrm{Br}$ J Urol. 1998;81:852-5.

4. Kim SY, Song SY, Kim MS, Lee JY, Lee HM, Choi HY, Yoo NJ, Lee $\mathrm{SH}$. Immunohistochemical analysis of Fas and FLIP in prostate cancers. APMIS. 2009;117:28-33.

5. Jiang J, Ulbright TM, Zhang S, Eckert GJ, Kao C, Gardner TA, Koch MO, Eble JN, Cheng L. Fas and Fas ligand expression is elevated in prostatic intraepithelial neoplasia and prostatic adenocarcinoma. Cancer. 2002;95:296-300.

6. Kimura K, Gelmann EP. Tumor necrosis factor-alpha and Fas activate complementary Fas-associated death domain-dependent pathways that enhance apoptosis induced by gamma-irradiation. J Biol Chem. 2000;275:8610-7.

7. Munshi A, Pappas G, Honda T, McDonnell TJ, Younes A, Li Y, Meyn RE. TRAIL (APO-2L) induces apoptosis in human prostate cancer cells inhibitable by Bcl-2. Oncogene. 2001;20:3757-65.

8. Nimmanapalli R, Perkins CL, Orlando M, O’Bryan E, Nguyen D, Bhalla KN. Pretreatment with paclitaxel enhances Apo-2 ligand/ tumor necrosis factor-related apoptosisinducing ligand-induced apoptosis of prostate cancer cells by inducing death receptors 4 and 5 protein levels. Cancer Res. 2001;61:759-63.
9. Irmler M, Thome M, Hahne M, Schneider P, Hofmann K, Steiner V, Bodmer JL, Schröter M, Burns K, Mattmann C, Rimoldi D, French LE, Tschopp J. Inhibition of death receptor signals by cellular FLIP. Nature. 1997;388:190-5.

10. Mawji IA, Simpson CD, Hurren R, Gronda M, Williams MA, Filmus J, Jonkman J, Da Costa RS, Wilson BC, Thomas MP, Reed JC, Glinsky GV, Schimmer AD. Critical role for Fasassociated death domain-like interleukin-1-converting enzymelike inhibitory protein in anoikis resistance and distant tumor formation. J Natl Cancer Inst. 2007;99:811-22.

11. Santourlidis S, Warskulat U, Florl AR, Maas S, Pulte T, Fischer J, Müller W, Schulz WA. Hypermethylation of the tumor necrosis factor receptor superfamily 6 (APT1, Fas, CD95/Apo-1) gene promoter at $\mathrm{rel} /$ nuclear factor $\mathrm{kB}$ sites in prostatic carcinoma. Mol Carcinog. 2001;32:36-43.

12. Hughes SJ, Nambu Y, Soldes OS, Hamstra D, Rehemtulla A, Iannettoni MD, Orringer MB, Beer DG. Fas/APO-1 (CD95) is not translocated to the cell membrane in esophageal adenocarcinoma. Cancer Res. 1997;57:5571-8.

13. Nambu Y, Hughes SJ, Rehemtulla A, Hamstra D, Orringer MB, Beer DG. Lack of cell surface Fas/APO-1 expression in pulmonary adenocarcinomas. J Clin Invest. 1998;101:1102-10.

14. Higaki K, Yano H, Kojiro M. Fas antigen expression and its relationship with apoptosis in human hepatocellular carcinoma and noncancerous tissues. Am J Pathol. 1996;149:429-37.

15. Cunha GR, Hayward SW, Wang YZ, Ricke WA. Role of the stromal microenvironment in carcinogenesis of the prostate. Int J Cancer. 2003;107:1-10.

16. Bavik C, Coleman I, Dean JP, Knudsen B, Plymate S, Nelson PS. The gene expression program of prostate fibroblast senescence modulates neoplastic epithelial cell proliferation through paracrine mechanisms. Cancer Res. 2006;66:794-802.

17. Begley L, Keeney D, Beheshti B, Squire JA, Kant R, Chaib H, MacDonald JW, Rhim J, Macoska JA. Concordant copy number and transcriptional activity of genes mapping to derivative chromosomes 8 during cellular immortalization in vitro. Genes Chromosomes Cancer. 2006;45:136-46.

18. Anees M, Horak P, El-Gazzar A, Susani M, Heinze G, Perco P, Loda M, Lis R, Krainer M, Oh WK. Recurrence-free survival in prostate cancer is related to increased stromal TRAIL expression. Cancer. 2011;117:1172-82.

19. Lee SH, Shin MS, Lee JY, Park WS, Kim SY, Jang JJ, Dong SM, $\mathrm{Na}$ EY, Kim CS, Kim SH, Yoo NJ. In vivo expression of soluble Fas and FAP-1: Possible mechanisms of Fas resistance in human hepatoblastomas. J Pathol. 1999;188:207-12.

20. Sato T, Irie S, Kitada S, Reed JC. FAP-1: A protein tyrosine phosphatase that associates with Fas. Science. 1995;268:411-5.

21. Thomas RK, Kallenborn A, Wickenhauser C, Schultze JL, Draube A, Vockerodt M, Re D, Diehl V, Wolf J. Constitutive expression of c-FLIP in Hodgkin and Reed-Sternberg cells. Am J Pathol. 2002;160:1521-8.

22. Ryu BK, Lee MG, Chi SG, Kim YW, Park JH. Increased expression of cFLIP(L) in colonic adenocarcinoma. J Pathol. 2001;194:15-9.

23. Griffith TS, Chin WA, Jackson GC, Lynch DH, Kubin MZ. Intracellular regulation of TRAIL induced apoptosis in human melanoma cells. J Immunol. 1998;161:2833-40. 
24. Lee SH, Kim HS, Kim SY, Lee YS, Park WS, Kim SH, Lee JY, Yoo NJ. Increased expression of FLIP, an inhibitor of Fas-mediated apoptosis, in stomach cancer. APMIS. 2003;111:309-14.

25. Zhang X, Jin TG, Yang H, DeWolf WC, Khosravi-Far R, Olumi AF. Persistent c-FLIP(L) expression is necessary and sufficient to maintain resistance to tumor necrosis factor-related apoptosisinducing ligand-mediated apoptosis in prostate cancer. Cancer Res. 2004;64:7086-91.

26. Shin MS, Park WS, Kim SY, Kim HS, Kang SJ, Song KY, Park JY, Dong SM, Pi JH, Oh RR, Lee JY, Yoo NJ, Lee SH. Alterations of Fas (Apo-1/CD95) gene in cutaneous malignant melanoma. Am J Pathol. 1999;154:1785-91.

27. Kim HS, Lee JW, Soung YH, Park WS, Kim SY, Lee JH, Park JY, Cho YG, Kim CJ, Jeong SW, Nam SW, Kim SH, Lee JY, Yoo NJ, Lee SH. Inactivating mutations of caspase- 8 gene in colorectal carcinomas. Gastroenterology. 2003;125:708-15.

28. Shin MS, Kim HS, Kang CS, Park WS, Kim SY, Lee SN, Lee JH, Park JY, Jang JJ, Kim CW, Kim SH, Lee JY, Yoo NJ, Lee $\mathrm{SH}$. Inactivating mutations of CASP10 gene in non-Hodgkin lymphomas. Blood. 2002;99:4094-9.

29. Müllauer L, Mosberger I, Grusch M, Rudas M, Chott A. Fas ligand is expressed in normal breast epithelial cells and is frequently upregulated in breast cancer. J Pathol. 2000;190:20-30.

30. Hahne M, Rimoldi D, Schröter M, Romero P, Schreier M, French LE, Schneider P, Bornand T, Fontana A, Lienard D, Cerottini J, Tschopp J. Melanoma cell expression of Fas (Apo-1/CD95) ligand: Implications for tumor immune escape. Science. 1996;274:13636.

31. Ashkenazi A, Dixit VM. Death receptors: Signaling and modulation. Science. 1998;281:1305-8.

32. Griffith TS, Lynch DH. TRAIL: A molecule with multiple receptors and control mechanisms. Curr Opin Immunol. 1998;10:559-63.

33. Nesterov A, Lu X, Johnson M, Miller GJ, Ivashchenko Y, Kraft AS. Elevated AKT activity protects the prostate cancer cell line LNCaP from TRAIL-induced apoptosis. J Biol Chem. 2001;276:1076774.

34. Sheridan JP, Marsters SA, Pitti RM, Gurney A, Skubatch M, Baldwin D, Ramakrishnan L, Gray CL, Baker K, Wood WI, Goddard AD, Godowski P, Ashkenazi A. Control of TRAILinduced apoptosis by a family of signaling and decoy receptors. Science. 1997;277:818-21.
35. French LE, Tschopp J. The TRAIL to selective tumor death. Nat Med. 1999;5:146-7.

36. Sanlioglu AD, Koksal IT, Karacay B, Baykara M, Luleci G, Sanlioglu S. Adenovirus-mediated IKKbetaKA expression sensitizes prostate carcinoma cells to TRAIL-induced apoptosis. Cancer Gene Ther. 2006;13:21-31.

37. Sanlioglu AD, Dirice E, Aydin C, Erin N, Koksoy S, Sanlioglu S. Surface TRAIL decoy receptor-4 expression is correlated with TRAIL resistance in MCF7 breast cancer cells. BMC Cancer. 2005;5:54.

38. Sanlioglu AD, Koksal IT, Ciftcioglu A, Baykara M, Luleci G, Sanlioglu S. Differential expression of TRAIL and its receptors in benign and malignant prostate tissues. J Urol. 2007;177:359-64.

39. Shankar S, Chen X, Srivastava RK. Effects of sequential treatments with hemotherapeutic drugs followed by TRAIL on prostate cancer in vitro and in vivo. Prostate. 2005;62:165-86.

40. Sridhar S, Ali AA, Liang Y, El Etreby MF, Lewis RW, Kumar MV. Differential expression of members of the tumor necrosis factor alpha-related apoptosis-inducing ligand pathway in prostate cancer cells. Cancer Res. 2001;61:7179-83.

41. Shankar S, Singh TR, Srivastava RK. Ionizing radiation enhances the therapeutic potential of TRAIL in prostate cancer in vitro and in vivo: Intracellular mechanisms. Prostate. 2004;61:35-49.

42. Tuxhorn JA, Ayala GE, Smith MJ, Smith VC, Dang TD, Rowley DR. Reactive stroma in human prostate cancer: Induction of myofibroblast phenotype and extracellular matrix remodeling. Clin Cancer Res. 2002;8:2912-23.

43. Dean JP, Nelson PS. Profiling influences of senescent and aged fibroblasts on prostate carcinogenesis. Br J Cancer. 2008;98:2459.

44. Risbridger GP, Taylor RA. Minireview: Regulation of prostatic stem cells by stromal niche in health and disease. Endocrinology. 2008;149:4303-6.

45. Shimada K, Nakamura M, Matsuyoshi S, Ishida E, Konishi N. Specific positive and negative effects of FLIP on cell survival in human prostate cancer. Carcinogenesis. 2006;27:1349-57. 